\title{
Analysis and Performance of Diesel Engine by Using Calophyllum Inophyllum Biodiesel
}

\author{
S. A. Ramesh ${ }^{1}$, K. Krishnakanth ${ }^{1}$, V. Premkumar ${ }^{2}$ \\ ${ }^{1}$ Assistant Professor, Department of mechanical engineering, Sasurie College of engineering, Tirupur-638056, Tamilnadu, India. \\ ${ }^{2}$ Department of mechanical engineering, Sasurie College of engineering, Tirupur-638056, Tamilnadu, India.
}

\begin{abstract}
In recent days there is a demand for petroleum based fuels because of the growth of industrial sectors and transportation. This can be overcome using the bio fuels instead of using the petroleum based. This type of bio-diesel can be prepared from the calophyllum inophyllumseed. In this type there are three treatments used to purify the seed oil. They are pre-treatment, post treatment and transesterification process. After this processes the acid contents, fatty acids are removed. Then the results of the oil are studied and find the best ratio of the diesel with the mixing of petroleum fuel.
\end{abstract}

Keywords: transesterification

\section{Introduction}

Current day's energy utilization is continuous because of the development of industries and transportation sectors, in that energy production and transport, the petroleum based products are mainly used, so the increase in the demand of petroleum based products. To overcome these situations by using alternative fuel like bio-diesel from vegetable oil or animal fat.

\section{Scope and Production}

The main red scope of the work to use callophulluminnophyllum vegetable oil is converted into biodiesel having three process they are pretreatment, post treatment and transeterification process using the catalyst are heterogeneous and homogeneous catalyst. Then the production of the bio-diesel by using both catalyst and compare the physical property of bio-diesel and judge the better catalyst for production of bio-diesel.

\section{Materials and Methods}

In this there are four types of process are needed, they are extraction of oil, pretreatment, transesterification and post treatment.

\section{Extraction of Oil}

The seed of the calophylluminnophyllum having high oil content on it, so the mechanical extraction is needed. The oil is non-edible oil then it shows dark green color and high viscosity with high free fatty acid level.

\section{Pre Treatment}

The viscosity, color and acid value of vegetable oil is different compare to other vegetable oil, so the process is to reduce both the viscosity and acid value.

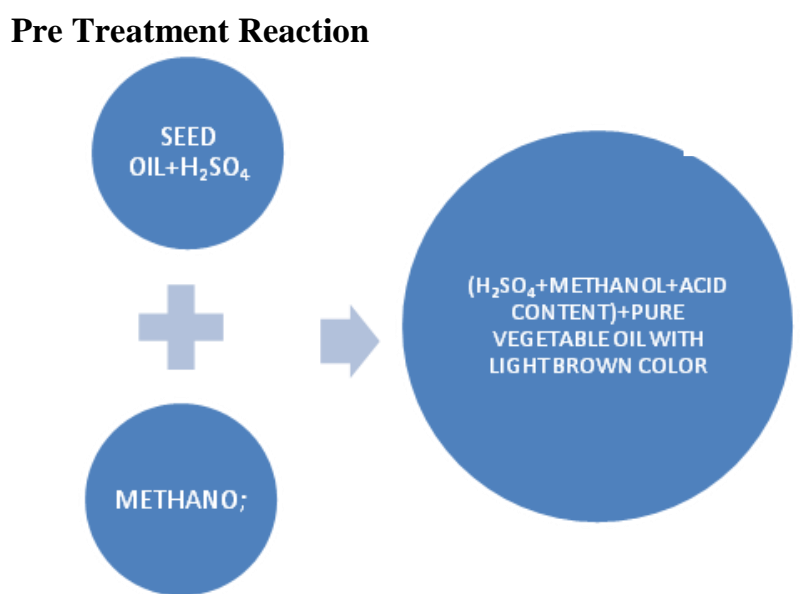

\section{Transesterification}

The main purpose of transesterification is to eliminate glycerol and reduce the viscosity of oil,

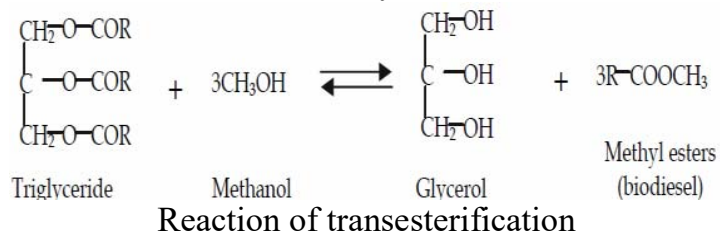

in that project methanol is taken as alcohol and both heterogeneous and homogeneous catalyst are used to do the transesterification process

\section{Post Treatment}

The process of removing glycerol, unreacted oil, and excess methanol is done by the adding of petroleum ether, methanol, water and heating up to the vaporization of methanol and water. That process only for biodiesel production under the use of homogeneous catalyst.

\section{Process Optimization and Properties}

- Transesterification heterogeneous catalyst optimization

- Transesterification homogeneous catalyst optimization 
Homogeneous and heterogeneous catalyst properties of the calophylluminophyllum biodiesel:

The property of the produced biodiesel is measured and it will be tabulated to optimize best one having better quality compare to other.

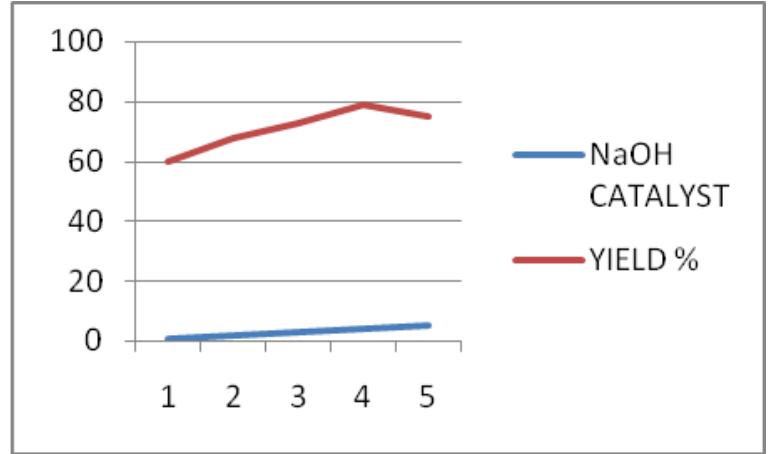

\section{Conclusion}

This study on comparison characteristics of calophylluminophyllum biodiesel by using heterogeneous v/s homogeneous catalyst are used to check the best and economic catalyst to be produce the biodiesel. While using the homogeneous catalyst in that biodiesel having better property but the post process will be carried on it, then using the heterogeneous catalyst in that biodiesel having somewhat best property but the post processing is no need for clean biodiesel, so we select the best catalyst for producing biodiesel is heterogeneous catalyst.

\section{References}

[1] SurbhiSemwal a, Ajay K. Arora b, Rajendra P. Badoni a, Deepak K. Tuli Biodiesel production using heterogeneous catalysts Review Bioresource Technology 102 (2011) 2151-2161

[2] Vasantha kumar SathyaSelvabala, Dinesh KiruphaSelvaraj, Jalagandeeswaran Kalimuthu, Premkumar Manickam Periyaraman, Sivanesan Subramanian Two-step biodiesel production from Calophylluminophyllum oil: Optimizationof modified bzeolite catalyzed pre-treatment Bio resource Technology 102 (2011) 1066-1072

[3] Abebe K. Endalew, YohannesKiros*, Rolando Zanzi Review Inorganic heterogeneous catalysts for biodiesel production from vegetable oils biomass and bioenergy 35 (2011) 3787e3809

[4] C.Senthilkumar, process parameter optimization and performance analysis of rabhanussativus methyl ester in diesel engine in journal of chemical and pharmaceutical sciences ISSN: 0974-2115

[5] A.P. Singh Chouhan, A.K. Sarma*Modern heterogeneous catalysts for biodiesel production: A comprehensive review, Renewable and Sustainable Energy Reviews 15 (2011) 4378- 43 